\title{
Critical Assessment indicators for measuring benefits of rural infrastructure investment in China
}

\author{
Li-Yin Shen ${ }^{1}$, M. ASCE, Wei-Sheng Lu $^{2}$, Yi Peng ${ }^{3, *}$, Shi-Jie Jiang ${ }^{4}$ \\ ${ }^{1}$ Professor, Department of Building and Real Estate, The Hong Kong Polytechnic \\ University, Hung Hom, Kowloon, Hong Kong, P. R. China, Email: \\ bsshen@polyu.edu.hk \\ ${ }^{2}$ Assistant Professor, Department of Real Estate and Construction, The University of \\ Hong Kong, Hong Kong, P. R. China, Email: wilsonlu@hku.hk \\ ${ }^{3}$ Phd Candidate, Corresponding Author, Department of Building and Real Estate, The \\ Hong Kong Polytechnic University, Hung Hom, Kowloon, Hong Kong, P. R. China, \\ Email: pengyihz@gmail.com \\ ${ }^{4}$ Postdoctoral Fellow, Department of Building and Real Estate, The Hong Kong \\ Polytechnic University, Email: cqaj@163.com
}

Abstract: Rural infrastructure is of vital importance for agricultural growth, economic development, and poverty alleviation, particularly in developing countries such as China. With the implementation of a Coordinated Urban-Rural Development Strategy, infrastructure investment has been tilted to rural areas in China. There is an urgent need to assess whether such an investment has induced the benefits as expected. Existing assessment research on rural infrastructure investment focuses mainly on economic benefits while neglecting its impacts on social and ecological aspects. This paper introduces a set of critical assessment indicators (CAIs) that can evaluate the multifaceted benefits of rural infrastructure investment in China. Research data were collected from a questionnaire survey to three groups of experts including government officers, professionals and business practitioners who are working in China's housing and urban-rural development sector. A Monte Carlo Simulation (MCS) is used to 
analyze the data. Based on the simulation, the Fuzzy Set theory is used for establishing the CAIs. The selected CAIs can help local government to make better decisions when investing in rural infrastructure in China. The indicators can also be generalized to provide valuable references for the investigation of rural infrastructure investment in other developing countries.

Keywords: Rural infrastructure; investment in infrastructure; critical assessment indicators (CAIs); Monte Carlo Simulation (MCS); Fuzzy Set theory; China

CE Database subject headings: Monte Carlo Method; Fuzzy Set; Infrastructure; Investments; Assessment; China 


\section{Introduction}

It is widely appreciated that infrastructure is the basic physical structures needed for the operation of a society, in both urban and rural areas. Urban infrastructure usually refers to systems generally owned and operated by municipalities or city governments, such as streets, water and electricity distribution facilities, sewers, etc (Schübeler, 1996). By contrast, rural infrastructure such as rural road, canal irrigation, rural electrification, water supply, telecommunication, etc. is located in rural areas to support rural development and living activities in these areas (Pouliquen, 1999). Governments throughout the world have well recognized the importance of infrastructure investment. Development of rural infrastructure is a major development priority, especially in developing counties (World Bank, 1994), and thus attracted a large amount of research interests. For example, Andersen and Shimokawa (2006) reported that the status of infrastructure stocks and services in most developing countries are far from sufficient and much poorer than that in developed countries. Jacoby (2000) suggested that providing extensive road access to markets would confer substantial benefits on average, especially to poor households in Nepal. Fan and Pardey (1997) pointed out that improving irrigation infrastructure brings more growth in agricultural outputs than land or labor does. Chandra and Thompson (2000) found that opening new interstate highways will not necessarily increase net economic activity in non-metropolitan regions.

Infrastructure construction has been rapidly developed in China. It was reported that 
the average annual growth rate of investment in infrastructure was around $33 \%$ between 1996 and 2000 (Dong, 2008). In the past, this investment was made on urban areas to support China's unprecedented urbanization ambition. Recently, a Coordinated Urban-Rural Development Strategy has been promoted in China. This strategy, by appreciating the remarkable imbalance between China's urban and rural development, aims to solve the problems of Agriculture, Rural Areas, and Farmers (also San Nong Problems) and achieve a compatible development of urban and rural areas (NDRC, 2005; Lu, 2006). As per the strategy, infrastructure investment has been tilted to the rural areas. Statistics show that the investment in rural infrastructure from the central government was about 18 billion USD in 2008 and 20 billion USD in $2009^{*}$ (NDRC, 2009). In parallel to this is the huge amount of investment from local governments.

The rural infrastructure investment in China has attracted increasing number of research studies, especially on its impact and effectiveness. Dong (2000) found that the investment in rural infrastructure improved the agriculture productivity. Fan and Zhang (2004) opined that the increase in rural infrastructure plays a more important role in narrowing the difference in rural development between the eastern, central and western parts of China. Other scholars (e.g. Liu et al., 2003; Hu and Fu, 2007) have addressed the contributions of investing in rural infrastructure such as technology, education, participation of farmers.

\footnotetext{
* Where the exchange rate is $1 \mathrm{USD}=6.8 \mathrm{RMB}$
} 
Notwithstanding the perceived benefits as shown above, the development of rural infrastructure in China is still comparatively slow. This is largely due to its low direct economic return. For example, Fox and Porca (2001) suggested that rates of return were generally low for rural road projects and even negative if the investment is not properly managed. Whilst it is still necessary to use economic indicators such as return on investment (ROI), it is vitally important to assess the rural infrastructure investment from a holistic view. This will encourage government, institutional investors, or private finance to participate in rural infrastructure development. Existing assessment research on rural infrastructure investment focuses mainly on economic benefits while neglecting its social and ecological impacts.

The aim of this research is to identify a set of critical assessment indicators (CAIs) for evaluating the multifaceted benefits of investment in rural infrastructure with particular reference to China. The research engaged the following four steps:

- Firstly, tentative assessment indicators (TAIs) were developed. They were filtered from a number of feasibility study reports on infrastructure investment in China. A pilot study was followed to assess the suitability of these indicators, and as a result a list of tentative assessment indicators was consolidated.

- Secondly, a questionnaire survey was conducted to collect data from various groups of experts for analyzing the significance of the assessment indicators. 
Experts were invited to indicate the significance of individual indicators by using nine points of Likert Scale.

- Thirdly, a Monte Carlo Simulation (MCS) was conducted to generate the data for further analysis based on the survey data from the questionnaire. A questionnaire survey, no matter how big the sample size is, only reflects opinions of limited number of experts. It is believed that the MCS could alleviate this problem.

- In the final stage, the critical assessment indicators (CAIs) are selected. Unlike traditional studies of this kind, the process of selecting CAIs involves uncertainties and fuzziness and the Fuzzy Set theory is used in the study.

\section{Tentative Assessment Indicators for Measuring the Benefits of Rural Infrastructure Investment}

Tentative assessment indicators (TAIs) for measuring the benefits of investment in rural infrastructure were identified by referring to official documents and various existing studies including Economic Evaluation Method and Parameters of Construction Projects by National Development and Reform Commission(NDRC, 2006), Economic Evaluation Cases of Construction Project by the former Ministry of

Construction(MOC, 2006), the research report "Quantitative Evaluation of Infrastructure Investment Effect" by Lin and Chen(2006), and the report "Social Evaluation Guidance for Investment Projects in China-Projects Financed by the World Bank and Asian Development Bank" by China International Engineering Consulting Corporation(CIECC, 2004). The TAIs were then refined through a pilot 
study by inviting the comments from various experts, including 10 experts from government departments, 18 from research \& higher education institutions, and 10 from enterprises and consultancy institutions. The pilot study led to the selection of 23 indicators as shown in Table 1, which were grouped under three categories: economic, social and environmental benefits.

$<$ Insert Table 1 here $>$

\section{Data Collection and Reliability Analysis}

Data for analyzing the significance of the TAIs listed in Table 1 were collected through a questionnaire survey conducted from July 2009 to August 2009 in China. The target respondents for the survey included government officers, professionals and business practitioners. 200 questionnaires were distributed and as a result 125 effective responses were received with a response rate of $63 \%$. Among the responses, 30 responses (24\%) were from government departments, 45 responses (36\%) from research \& higher education institutions, and 50 responses (40\%) from enterprises and consultancy institutions. Respondents were invited to indicate the level of significance of each assessment indicators by assigning a score between 1 and 9. Score "9" indicates most important, "7" important, "5" average, "3" unimportant and " 1 " negligible. The scores “ 8 ", “6”, “4”, “2” represent intermediate judgments between two adjacent judgments. By using the survey data, statistical calculations including means and standard deviation (SD) on the significance of assessment indicators were 
conducted, as shown in Table 2.

$<$ Insert Table 2 here $>$

The TAIs proposed in the questionnaire survey were grouped in three categories, namely, economic, social and environmental benefits. Statistical analyses were conducted to analyze data reliability in terms of the adequacy of the group classification and the consistence of the opinions among individual experts. In general, the adequacy of the indicator group classification is estimated by examining the consistency with which different items within a particular group express the same concept (de Vaus, 2002). Reliability of internal consistency is usually measured by Cronbach's coefficient $\alpha$. Previous study suggests that Cronbach's $\alpha$ shall be greater than 0.5 as a minimum, and ideally be greater than 0.7 (Ceng and Huang, 2005). In this survey, Cronbach's coefficients are 0.881 for the economic benefit group, 0.8 for the social and 0.945 for the environmental benefit group. As Cronbach's coefficients for all three groups of indicators are greater than 0.7 , it is considered that the questionnaire survey is reliable.

Furthermore, the analysis of variance (ANOVA) was conducted to examine whether the opinions of the three groups of respondents are consistent for each of the TAIs. If a probability value $p$ from ANOVA test below 0.05 is obtained, it normally suggests that there is a high degree of difference of opinions among the groups (SPSS Inc., 
2006). In other words, the groups can be considered independent. In this research, there are 4 indicators whose $p$ values are below 0.05 . It suggests that the differences of opinions for the 4 indicators among the three groups (government officers, professionals, and business practitioners) are significant. Therefore, the collected data samples must be considered separately.

\section{Selection of the Critical Assessment of Indicators (CAIs) Traditional Methodology for Selecting the CAIs}

A typical methodology for identifying critical indicators is to evaluate each indicator's relative significance value (Shen et al., 2004). The Likert Scale is commonly used in questionnaire survey for rating the relative significance of individual indicators through examining experts' opinion (Chan and Kumaraswamy, 1997). Relative significance values of indicators can be determined directly by the mean value of the scores assigned by experts in a survey or an index value in some more sophisticated cases. Often, a cut-off value of the relative significance is adopted in order to identify the critical indicators from a set of tentative indicators (Lu et al., 2008).

Although the traditional methodology provides an easy-to-use tool for identifying critical indicators, there are several deficiencies. First of all, data for analyzing critical indicators are collected from a questionnaire survey. Normally a Likert Scale is used to indicate experts' judgment, which is often subjective and fuzzy. Thus simple computation of mean value of these subjective scales might not be robust enough for 
the identification of critical indicators (Zadeh, 1965; Finetti, 1992). Second, survey sample size is often too small. Reviewers have always questioned sample size in studies of this nature while the answers are far from satisfaction. Third, the traditional cut-off value method to distinguish a critical or non-critical indicator overlooks the distribution of experts' views. This way might be invalid especially in some extreme conditions, e.g. a limited few samples with a big score allow the mean to pass the cut-off threshold but the concerned indicator cannot be treated as a critical one.

Standard Deviations (SD) can help perceive the deviations amongst experts' opinions but it was not normally used as a selection criterion. Monte Carlo Simulation (MCS) and Fuzzy Set theory can alleviate the above deficiencies.

\section{Increasing Sample Size Using Monte Carlo Simulation}

Monte Carlo Simulation (MCS) is a numerical method to solve problems in the areas

such as mathematics, physics, engineering and production management, by randomly sampling relevant stochastic variable or process (Xu, 1985). It is a useful tool applied in a situation where there is uncertain and uncontrollable input information whose probability distribution is known and can be handled analytically (Shen, 1993). In a questionnaire survey, ideally we should increase sample size to make sure the survey is more representative and meaningful if a full coverage of the target population is not possible. Research has suggested that there will be a convergence of parameters such as mean and standard deviations to their stable values as surveying samples increase. While in reality, it is very difficult to increase sample size until a convergence is 
achieved. MCS, however, can simulate the increasing samples of a questionnaire survey in a simulative environment. Through increasing the samplings, MCS can generate more data and lead to the convergence of parameters such as mean and standard deviations. Convergence is a valid way to confirm the efficiency of large numbers of samplings when conducting MCS (Cowles and Carlin, 1996). In other words, MCS can solve the problem of limited samples thus it is adopted in this paper.

There are various commercial packages available for conducting MCS analysis. In this research, the package Crystal Ball (2000 Professional Edition) was used. The generation of the probability distribution for the indicator $\mathrm{X}_{11}$ in the government group is taken as an example to show the run of MCS. In order to conduct MCS, we established the frequency and cumulative frequency of the response first. The frequency and cumulative frequency for the indicator $\mathrm{X}_{11}$ in government officers group are calculated and shown in Table 3.

$<$ Insert Table 3 here $>$

The frequency can be considered as the probability for an expert's view to occur within a discrete range 1 9. Based on the cumulative frequency in Table 3 , the operation of Crystal Ball Software leads to the generation of the distribution of $\mathrm{X}_{11}$ as shown in Figure 1. In this figure, the probability is considered as the average of the cumulative frequency in the specific interval. 
$<$ Insert Figure 1 here $>$

In order to confirm the probability distribution trend of $\mathrm{X}_{11}$ in government officers group, 100,000 simulations were conducted. The simulation process took nearly 2 minutes on T8100 (Duo CPU) /2.1G PC computer. The simulated probability distribution of $X_{11}$ in government officers group is shown in Figure 2. The simulated mean value begins to be stable when simulations reach 10,000 , while SD value is still a little fluctuant after 10,000 and begins to be stable when simulations reach 80,000 as shown in Figure 3.

$<$ Insert Figure 2 here $>$

$<$ Insert Figure 3 here $>$

Simulations have also been conducted for other indicators in different groups by following similar procedures. The significance score of each indicator by using simulation is shown in Table 4 . The results in the Table 4 are considered more reliable than those in Table 3 as simulation process generates much larger samples and approximates the convergence of mean and standard deviations as samples increase in a questionnaire survey. In general, the more the samples, the better the results. 
$<$ Insert Table 4 here $>$

\section{Selecting the CAIs Based on Fuzzy Set Theory}

Although MCS can solve the problem of small sample size, there is still another major deficiency in the identification of critical indicators through surveying. That is fuzziness in a questionnaire survey. For example, in this study, a 9-point Likert Scale is used for experts to judge the level of significance of each assessment indicators. Uncertainty and fuzziness are easily seen in experts' judgment. Fuzzy Set theory can take the challenge of the fuzziness in questionnaire survey. It utilizes membership probability to identify critical indicators. It thus can avoid the weakness of the traditional cut-off value method, since membership probability implies distribution of experts' views. Thanks to its advantages, Fuzzy Set theory is used in this paper to help find the CAIs. The data used for the fuzzy set analysis are the results of MCS conducted in previous section.

According to the Fuzzy Set theory, the symbol $\widetilde{A}$ is used to represent a set of critical assessment indicators, noted as CAI set. It is designed as a fuzzy set:

$$
\widetilde{A}=\mu_{\widetilde{A}}\left(x_{11}\right) / x_{11}+\mu_{\widetilde{A}}\left(x_{12}\right) / x_{12}+\ldots=\sum_{i=1}^{n} \sum_{j=1}^{m} \mu_{\widetilde{A}}\left(x_{i j}\right) / x_{i j} \quad \text { (Equation 1) }
$$

Where $x_{i j}$ is an indicator listed in Table 1. $n$ denotes the number of categories, which is 3 , and $m$ is the number of indicators under each category. $\mu_{\widetilde{A}}\left(x_{i j}\right)$ denotes the degree of membership of $x_{i j}$ in the fuzzy set $\tilde{A}$, and $\mu_{\tilde{A}}\left(x_{i j}\right) \in[0,1]$. As reference to the symbols of fuzzy set (Zimmermann, 2001), ' $/$ in $\mu_{\widetilde{A}}\left(x_{i j}\right) / x_{i j}$ indicates that the 
degree of membership of $x_{i j}$ is $\mu_{\widetilde{A}}\left(x_{i j}\right)$, and ' + ' might be seen as a logical operator "and".

As designed in the questionnaire, the significance of a specific indicator can be scored between 1 and 9 , the score of 5 is seen as a demarcation level for critical or not for the indicator. It is feasible to consider that the probability for an indicator's score over 5 is the criterion for an indicator to be included in CAIs fuzzy set. Based on Fuzzy Set theory, the probability for an indicator belonging to CAIs fuzzy set is the degree of membership of the indicator in the CAIs fuzzy set (Zimmermann, 2001). Hereby, the degree of membership $\mu_{\widetilde{A}}\left(x_{i j}\right)$ can be described as follows:

$\mu_{\widetilde{A}}\left(x_{i j}\right)=\int_{5}^{\infty} P_{x_{i j}} d x=1-P_{f}$

Where $P_{x_{i j}}$ represents the probability density of a particular indicator that occurs in the simulation result, and $P_{f}$ indicates that the possibility that the indicator does not belong to CAIs group. As a result, the degree of membership $\mu_{\widetilde{A}}\left(x_{i j}\right)$ can be calculated using Equation 2.

However, the ANOVA test suggests that the data from the three groups (government officials, professionals, and business practitioners) must be considered separately. Thus there are three different CAI fuzzy sets, represented by $\widetilde{A}_{G}, \widetilde{A}_{P}$ and $\widetilde{A}_{B}$. According to Equation 2, the degree of membership $\mu_{\widetilde{A}}\left(x_{i j}\right)$ can be computed. The results of $\mu_{\widetilde{A}_{G}}, \quad \mu_{\widetilde{A}_{p}}$ and $\mu_{\widetilde{A}_{B}}$ are shown in Table 5 . 
$<$ Insert Table 5 here $>$

According to the definition of the union operator in fuzzy theory by Yager (1980), overall CAIs fuzzy set can be described as follows:

$$
\widetilde{A}=\widetilde{A}_{G} \cup \widetilde{A}_{P} \cup \widetilde{A}_{B}=\left\{x, \mu_{\widetilde{A}_{G} \cup \tilde{A}_{P} \cup \tilde{A}_{B}} \mid x \in X\right\}
$$

where

$$
\mu_{\widetilde{A}_{G} \cup \widetilde{A}_{p} \cup \widetilde{A}_{B}}=\min \left\{1,\left(\mu_{\widetilde{A}_{G}}(x)^{p}+\mu_{\widetilde{A}_{p}}(x)^{p}+\mu_{\widetilde{A}_{B}}(x)^{p}\right)^{1 / p}\right\}, p \geq 1
$$

where $p$ denotes the number of indicators. In this study $p$ is 23 . Therefore, the integrated result $\mu_{\widetilde{A}}\left(x_{i j}\right)$ was obtained from the union of $\mu_{\widetilde{A}_{G}}, \mu_{\widetilde{A}_{P}}$ and $\mu_{\widetilde{A}_{B}}$ based on Equation 4. The results of $\mu_{\widetilde{A}}\left(x_{i j}\right)$ are shown in the last column of Table 5.

To find out the CAIs for measuring the benefits of investment in rural infrastructure, the $\lambda$-cut set approach is adopted. A benchmark value $\lambda$ should be preset. The indicator $x_{i j}$ shall be considered as a critical assessment indicator, if its degree of membership passes over the preset value $\lambda$. The benchmark value $\lambda$ may impact the numbers of indicators falling into the CAIs set. If $\lambda=0$, then all the indicators belong to the CAI set, yet, if $\lambda=1$, then there are few indicators or even none in the CAI set. In this study, $\lambda=0.85$, a commonly used threshold in the fuzzy set theory (e.g. Abunawass et al., 1998; Uysal and Yarman-Vural, 2003), is adopted as the criterion to select CAIs from Table 5. The procedures for identifying CAIs can be demonstrated in a flow chart, as shown in Figure 4. 
$<$ Insert Figure 4 here $>$

\section{Discussions and Results}

\section{Implications of the CAIs}

Following the procedures in Figure 4, eight CAIs were selected as shown below,

which are ranked by the degree of membership in descending order:

- Capability to provide associated facilities $X_{23}$ (in social benefit group, Degree of membership: 1.00)

- Employment status $X_{21}$ (in social benefit group, Degree of membership: 1.00)

- Air pollution index $X_{31}$ (in environmental benefit group, Degree of membership:

- Surface water pollution degree $X_{32}$ (in environmental benefit group, Degree of membership: 0.923)

- Water and soil loss impact $X_{35}$ (in environmental benefit group, Degree of membership: 0.884)

- Safety benefit $X_{25}$ (in social benefit group, Degree of membership: 0.864)

- Living standard and quality $X_{22}$ (in social benefit group, Degree of membership: 0.859)

- Solid waste pollution degree $X_{33}$ (in environmental benefit group, Degree of membership: 0.856) 
In social benefit group, there are 4 CAIs, where the indicator Capability to provide associated facilities $\left(X_{23}\right)$ is ranked as the most important indicator. As the distribution of rural infrastructure is sparse and the benefited people is limited with its low efficiency (Zhou and Kuang, 2007), Capacity to provide associated facilities is essential for measuring the benefit of investment in rural infrastructure. Other critical indicators in the social benefit group include Employment status $\left(X_{21}\right)$, Safety benefit $\left(X_{25}\right)$, Living standard and quality $\left(X_{22}\right)$.

There are also 4 CAIs in the environmental benefit group. The indicator Air pollution index $\left(X_{31}\right)$ is ranked the most important. Air pollution has become a big problem due to inadequate infrastructure and technology (Swanson et al., 2001), and therefore it has aroused increasing concern in China. Other critical indicators in the environmental benefit group include Surface water pollution degree $\left(X_{32}\right)$, Water and soil loss impact $\left(X_{35}\right)$ and Solid waste pollution degree $\left(X_{33}\right)$. In China, environmental impact assessment (EIA) on infrastructure projects has been enforced by government since 2003. In line with this, the Law of the People's Republic of China on Appraising of Environment Impacts has been implemented since then. As a result, within this context, it is important to consider the environmental benefits when making decision on rural infrastructure investment.

It is worthwhile to note that economic benefit group has been filtered out altogether in the selected CAIs. The reason is that the direct financial income is little or even null 
for rural infrastructure investment in China (Meng and $\mathrm{Xu}, 2008$ ). The investment does not aim to make profit, but rather pursuing general public's interest in China (Canning, 1998; Li, 2003). The main investors in rural infrastructure in China are rural collective organizations and local people, whose investment is the form of labor or allotment. These were not calculated on monetary basis. Both the investor and owner do not expect financial return. This is similar to those infrastructure projects sponsored by the World Bank or Asia Development Bank, where the sponsors usually only require the principal to be returned. As a result, it is not surprise to notice that no financial benefit indicators are included in the CAI set.

The above discussion demonstrates that the CAIs selected should be given more attention when considering the benefits of investment in rural infrastructure under the specific circumstance of China. The selected CAIs can help local government to make better decision when investing in rural infrastructure in China. Also, it is valuable reference for engaging similar studies in other countries.

\section{Implications to Research Methodology}

The traditional analysis of questionnaire survey is often challenged owing to its small sample size. A major contribution of this paper is the innovative application of Monte Carlo Simulation (MCS) to solve the problem. The large number of simulations can generate more data and lead to convergence, which simulates the situation where more surveys are conducted. However, MCS is not a panacea to alleviate the problem 
of small sample size in questionnaire survey studies. Garbage in, garbage out. In order to achieve a good simulation result, the initial survey data must obey the overall distribution. That is to say, we must conduct a robust questionnaire survey, where the survey results are random enough with sufficient samples to reflect the overall distribution. Otherwise, the distribution could not represent the real situation when surveying samples are increased, and hence MCS is not applicable.

Furthermore, an experiment should be designed to validate the effectiveness of the innovative application of MCS. First a questionnaire survey with a limited sample for example 500 is conducted, and MCS is run to get the data and perform preset analysis. Second, the same survey with larger samples such as 1000 is conducted, and preset analysis is conducted directly without MCS. At last, the effectiveness can be analyzed by comparing the results in the two conditions.

The traditional way to select critical indicators using a cut-off value overlooks the fuzziness in experts' opinions. In this paper, Fuzzy Set theory is utilized to reflect the fuzzy nature in questionnaire survey. It utilizes membership probability to identify the critical indicators. It thus can avoid the weakness of the traditional cut-off value method, since membership probability implies distribution of experts' views. The combination use of MCS and Fuzzy Set theory can help improve the adequacy of selecting CAIs, which is a good reference for others in a similar task. 


\section{Conclusions}

Rural infrastructure projects play a major role in rural development and living activities in rural areas. The benefits of investment in rural infrastructure should be properly assessed. Due to lack of effective assessment indicators available in practice, the benefits usually are not assessed effectively. This paper introduces a set of critical assessment indicators (CAIs) for measuring the benefits of investment in rural infrastructure. The eight CAIs can help decision-makers to identify an optimal solution amongst alternative options for the sustainable development of infrastructure projects in rural areas of China.

Furthermore, this study provides an alternative methodology to analyze the questionnaire and select out the critical assessment indicators. Monte Carlo Simulation is undertaken to analyze the questionnaire data, which remedies some deficiencies when conducting questionnaire survey. Fuzzy Set theory is adopted to develop the CAIs, which increases the adequacy of indicators selection. The innovative application of the MCS into questionnaire analysis and Fuzzy Set Theory into critical indicators identification can be beneficial to other studies in the similar research field.

\section{Acknowledgement}

The research team wishes to extend the thanks to the experts from different professions who have supported this research by taking part in rounds of 
questionnaire surveys. Special thanks also go to the funding body The Hong Kong Polytechnic University.

\section{Reference}

Abunawass, A. M., Bhell, O. S., Ding, M., et al. (1998). "Fuzzy clustering improves convergence of the backpropagation algorithm.” Symposium on Applied Computing, Proceedings of the 1998 ACM symposium on Applied Computing, Atlanta, Georgia, United States, 277-281.

Andersen, P. P., Shimokawa, S. (2006). "Rural infrastructure and agricultural development."

http://siteresources.worldbank.org/INTDECABCTOK2006/Resources/Per_Pinstrup Andersen_Rural_Infrastructure.pdf $\left(11^{\text {th }}\right.$ Dec. 2009).

Canning, D. (1998). “A database of world stocks of infrastructure.” The World Bank Economic Review, 12(3), 529-547.

Ceng, W. Y., Huang, B. Y. (2005). "Analysis on the reliability and validity of questionnaire.” Forum of Statistics and Information, 20(6), 11-16.

Chan, D. W. M., Kumaraswamy, M. M. (1997). “A comparative study of causes of time overrun in Hong Kong construction projects." International Journal of Project Management, 15(1), 55-63.

Chandra, A., Thompson, E. (2000). "Does public infrastructure affect economic activity? Evidence from the rural interstate highway system.” Regional Science and Urban Economics, 30(4), 457-490. 
China International Engineering Consulting Corporation(CIECC). (2004). "Social Evaluation Guidance for Investment Projects in China-Projects Financed by the World Bank and Asian Development Bank.” China Planning Press, Beijing.

Cowles, M. K., Carlin, B. P. (1996). "Markov chain Monte Carlo convergence diagnostics: A comparative review." Journal of the American Statistical Association, 91(434), 883-904.

De Vaus, D. (2002). Analyzing social science data. SAGE Publications Ltd, London.

Dong, X. Y. (2000). "Public investment, social services and productivity of Chinese household farms.” Journal of Development Studies, 36(3), 100-123.

Dong, Z. K. (2008). “Change of investment in rural infrastructure in China between 1950 and 2006." Researches in Chinese Economic History, (3), 29-37.

Fan, S. G., Pardey, P. G. (1997). "Research, productivity, and output growth in Chinese agriculture.” Journal of Development Economics, 53(1), 115-137.

Fan, S. G., Zhang, X. B. (2004). "Infrastructure and regional economic development in rural China." China Economic Review, 15(2), 203-214.

Finetti, B. D. (1992). "Foresight: Its logical laws, its subjective sources." Breakthroughs in statistics, Kotz, S. and Johnson, N. L.(eds.). Springer-Verlag, New York, 134-174.

Fox, W. F., Porca, S. (2001). "Investing in rural infrastructure." International Regional Science Review, 24(1): 103-133.

Hu, Z. H., Fu, A. M. (2007). "Rural Public Investment, Rural Household's Consumption and Economic Growth in Rural Areas." South China Journal of 
Economics, (5), 5-13.

Jacoby, H. G. (2000). "Access to markets and the benefits of rural roads." The Economic Journal, 110, 713-737.

Li, R. (2003). "Quantitative analysis of investment in rural public infrastructure." Journal of Agrotechnical Economics, (2), 5-9.

Lin, X. Y., Chen, Y. X. (2006). "Quantitative Evaluation of Infrastructure Investment Effect.” Tsinghua University Press and Beijing Jiaotong University Press, Beijing.

Liu, X. Y., Xin, X., Mao, X. F. (2003). "The Impact of Rural Infrastructure Investments on Household Income and Expenditure in Poverty-stricken Area." China Rural Survey, (1), 31-35.

Lu, W. S. (2006), A system for assessing and communicating contractors’ competitiveness, Ph.D. thesis, Hong Kong Polytechnic University, Hong Kong. Lu, W. S., Shen, L. Y., Yam, M. C. H. (2008). "Critical success factors for competitiveness of contractors: China study." Journal of Construction Engineering and Management, 134(12), 972-982.

Meng, Q. C., Xu, X. D. (2008). “The Empirical Analysis of Investment Returns of Rural Productive Infrastructure.” Yangtze River, (12), 106-108.

National Development and Reform Commission(NDRC). (2005). "Exploring into the Coordinated Urban-Rural Development strategy.”

http://www.sdpc.gov.cn/zjgx/t20051130_52160.htm (25 $5^{\text {th }}$ May. 2010).

National Development and Reform Commission(NDRC). (2006). "Economic Evaluation Method and Parameter of Construction Projects" ( $3^{\text {rd }}$ edition), China 
Planning Press, Beijing.

National Development and Reform Commission(NDRC). (2009). "Rural infrastructure development report (2009).”

http://www.ndrc.gov.cn/gzdt/W020090923423322709226.pdf(28 $8^{\text {th }}$ Dec. 2009).

Pouliquen, L. Y. (1999). "Rural infrastructure from a World Bank perspective: a knowledge management framework.” The World Bank, Washington D. C.

Schübeler, P. (1996). "Participation and partnership in urban infrastructure management." The World Bank, Washington D. C.

Shen, L. Y. (1993). "Simulation in construction estimation." Working paper No. 8. The Hong Kong Polytechnic University, 15.

Shen, L. Y., Lu, W. S., Yam, M. C. H. (2004). “Contractor key competitiveness indicators: A China study." Journal of Construction Engineering and Management, 132(4), 416-424.

SPSS Inc. (2006). “SPSS 15.0 for Windows brief guide.” Prentice-Hall, Englewood Cliffs, N. J.

Swanson, K. E., Kuhn, R. G., Xu, W. (2001). "Environmental policy implementation in rural China: A case study of Yuhang, Zhejiang.” Environmental Management, 27(4), $481-491$.

Ministry of Construction(MOC). (2006). "Economic Evaluation Cases of Construction Project.” China Planning Press, Beijing.

Uysal, M., Yarman-Vural, F. T. (2003).“Selection of the Best Representative Feature and Membership Assignment for Content-Based Fuzzy Image Database.” Lecture 
Notes in Computer Science, Springer Berlin / Heidelberg, 141-151.

World Bank (1994). "World development report 1994: Infrastructure for development." Oxford University Press, New York.

Xu, Z. J. (1985). The method of Monte Carlo. The Science \& Technology Press in Shanghai, Shanghai.

Yager, R. R. (1980). “On a general class of Fuzzy Connectives.” Fuzzy Sets and Systems, 4(3), 235-242.

Zadeh, L. A. (1965). “Fuzzy sets.” Information and Control, 8(3), 338-353.

Zhou, H. M., Kuang, Y. P. (2007). "Analysis of investment in rural infrastructure.” Journal of Hunan Agricultural University (Social Sciences), 8(3), 26-29.

Zimmermann, H. J. (2001). Fuzzy set theory and its application ( $4^{\text {th }}$ edition). Kluwer Academic Publishers, Boston/Dordrecht/London, 11-21, 133-138. 


\section{Appendixes}

Table 1 Evaluation Indicators for measuring the benefits of infrastructure investment in rural areas

\begin{tabular}{|c|c|c|}
\hline $\begin{array}{l}\text { Type of } \\
\text { indicators }\end{array}$ & Indicators & Code \\
\hline \multirow{7}{*}{$\begin{array}{l}\text { Economic } \\
\text { benefit }\end{array}$} & IRR (Internal Rate of Return) & $\mathrm{X}_{11}$ \\
\hline & NPV (Net Present Value) & $\mathrm{X}_{12}$ \\
\hline & Payback (dynamic) & $\mathrm{X}_{13}$ \\
\hline & Loan repayment period & $\mathrm{X}_{14}$ \\
\hline & EIRR (Economic Internal Rate of Return) & $\mathrm{X}_{15}$ \\
\hline & ENPV (Economic Net Present Value) & $\mathrm{X}_{16}$ \\
\hline & (Direct and indirect) benefit-cost ratio of project & $\mathrm{X}_{17}$ \\
\hline \multirow[t]{8}{*}{ Social benefit } & Employment status & $\mathrm{X}_{21}$ \\
\hline & Living standard and quality (expressed by Engel Indicator) & $\mathrm{X}_{22}$ \\
\hline & $\begin{array}{l}\text { Capability to provide associated facilities (expressed by prevalence } \\
\text { percentage) }\end{array}$ & $\mathrm{X}_{23}$ \\
\hline & Culture and education level, hygiene and health level & $\mathrm{X}_{24}$ \\
\hline & Safety benefit & $\mathrm{X}_{25}$ \\
\hline & $\begin{array}{l}\text { Amount of benefit compensation of project stake holders and } \\
\text { underprivileged groups }\end{array}$ & $\mathrm{X}_{26}$ \\
\hline & Mutual adaptability indicator & $\mathrm{X}_{27}$ \\
\hline & Social risk level (expressed by social risk evaluation value) & $\mathrm{X}_{28}$ \\
\hline \multirow{8}{*}{$\begin{array}{l}\text { Environmental } \\
\text { benefit }\end{array}$} & Air pollution index & $\mathrm{X}_{31}$ \\
\hline & Surface water pollution degree & $\mathrm{X}_{32}$ \\
\hline & Solid waste pollution degree & $\mathrm{X}_{33}$ \\
\hline & Noise pollution index & $\mathrm{X}_{34}$ \\
\hline & Water and soil loss impact & $\mathrm{X}_{35}$ \\
\hline & Cultural relic and heritage preservation percentage & $\mathrm{X}_{36}$ \\
\hline & Energy saving percentage & $\mathrm{X}_{37}$ \\
\hline & Recycled use percentage of wastes (or wastewater) & $\mathrm{X}_{38}$ \\
\hline
\end{tabular}


Table 2 The significance score of indicators

\begin{tabular}{|c|c|c|c|c|c|c|c|c|c|}
\hline \multirow[t]{2}{*}{$\begin{array}{l}\text { Type of } \\
\text { indicators }\end{array}$} & \multirow[t]{2}{*}{ Indicators } & \multicolumn{2}{|c|}{ All $(\mathrm{N}=125)$} & \multicolumn{2}{|c|}{$\begin{array}{c}\text { Government } \\
\text { officers } \\
(\mathrm{N}=30)\end{array}$} & \multicolumn{2}{|c|}{$\begin{array}{l}\text { Professionals } \\
\qquad(\mathrm{N}=45)\end{array}$} & \multicolumn{2}{|c|}{$\begin{array}{c}\text { Business } \\
\text { practitioners } \\
(\mathrm{N}=50)\end{array}$} \\
\hline & & Mean & $\mathrm{SD}$ & Mean & $\mathrm{SD}$ & Mean & $\mathrm{SD}$ & Mean & $\mathrm{SD}$ \\
\hline \multirow{7}{*}{$\begin{array}{l}\text { Economic } \\
\text { benefit }\end{array}$} & $\mathrm{X}_{11}$ & 6.22 & 1.67 & 5.63 & 1.85 & 6.38 & 1.75 & 6.44 & 1.43 \\
\hline & $\mathrm{X}_{12}$ & 6.08 & 1.63 & 5.57 & 1.59 & 6.31 & 1.81 & 6.18 & 1.45 \\
\hline & $\mathrm{X}_{13}$ & 6.37 & 1.89 & 5.97 & 1.79 & 6.47 & 2.03 & 6.52 & 1.82 \\
\hline & $\mathrm{X}_{14}$ & 5.92 & 1.58 & 5.23 & 1.59 & 5.87 & 1.47 & 6.38 & 1.55 \\
\hline & $\mathrm{X}_{15}$ & 5.56 & 1.60 & 4.97 & 1.59 & 5.58 & 1.66 & 5.90 & 1.49 \\
\hline & $\mathrm{X}_{16}$ & 5.54 & 1.57 & 5.07 & 1.34 & 5.49 & 1.79 & 5.88 & 1.42 \\
\hline & $\mathrm{X}_{17}$ & 5.86 & 1.53 & 5.97 & 1.83 & 5.62 & 1.37 & 6.00 & 1.47 \\
\hline \multirow[t]{8}{*}{ Social benefit } & $\mathrm{X}_{21}$ & 6.80 & 1.50 & 6.87 & 1.48 & 7.00 & 1.43 & 6.58 & 1.58 \\
\hline & $\mathrm{X}_{22}$ & 6.82 & 1.61 & 6.57 & 1.70 & 6.51 & 1.65 & 7.26 & 1.45 \\
\hline & $\mathrm{X}_{23}$ & 7.44 & 1.25 & 7.20 & 1.32 & 7.27 & 1.29 & 7.74 & 1.14 \\
\hline & $\mathrm{X}_{24}$ & 6.63 & 1.69 & 6.40 & 1.63 & 6.38 & 1.67 & 7.00 & 1.70 \\
\hline & $\mathrm{X}_{25}$ & 6.82 & 1.76 & 6.60 & 1.94 & 6.16 & 1.48 & 7.56 & 1.64 \\
\hline & $\mathrm{X}_{26}$ & 6.58 & 1.70 & 6.57 & 1.94 & 6.16 & 1.71 & 6.96 & 1.46 \\
\hline & $X_{27}$ & 6.14 & 1.55 & 6.07 & 1.66 & 6.31 & 1.41 & 6.02 & 1.61 \\
\hline & $\mathrm{X}_{28}$ & 5.98 & 1.81 & 5.53 & 1.83 & 6.00 & 1.75 & 6.22 & 1.84 \\
\hline \multirow{8}{*}{$\begin{array}{l}\text { Environmental } \\
\text { benefit }\end{array}$} & $\mathrm{X}_{31}$ & 7.15 & 1.57 & 6.83 & 1.66 & 7.09 & 1.31 & 7.40 & 1.70 \\
\hline & $\mathrm{X}_{32}$ & 7.22 & 1.61 & 6.83 & 1.72 & 7.29 & 1.41 & 7.40 & 1.70 \\
\hline & $X_{33}$ & 7.07 & 1.62 & 6.70 & 1.80 & 7.02 & 1.44 & 7.34 & 1.65 \\
\hline & $\mathrm{X}_{34}$ & 6.706 & 1.76 & 6.67 & 1.81 & 6.51 & 1.66 & 6.90 & 1.84 \\
\hline & $\mathrm{X}_{35}$ & 6.86 & 1.66 & 6.50 & 1.66 & 6.67 & 1.55 & 7.24 & 1.71 \\
\hline & $\mathrm{X}_{36}$ & 5.99 & 1.96 & 5.70 & 2.10 & 5.71 & 1.83 & 6.42 & 1.95 \\
\hline & $\mathrm{X}_{37}$ & 6.696 & 1.70 & 6.90 & 1.84 & 6.33 & 1.41 & 6.90 & 1.82 \\
\hline & $\mathrm{X}_{38}$ & 6.40 & 1.93 & 6.37 & 2.04 & 6.38 & 1.60 & 6.44 & 2.16 \\
\hline
\end{tabular}


Table 3 The cumulative frequency of $X_{11}$ in government group

\begin{tabular}{cccccccccc}
\hline Number & 1 & 2 & 3 & 4 & 5 & 6 & 7 & 8 & 9 \\
\hline $\begin{array}{c}\text { Frequency } \\
\text { Cumulative }\end{array}$ & 0.067 & 0 & 0.066 & 0 & 0.334 & 0.166 & 0.267 & 0.067 & 0.033 \\
Frequency & 0.067 & 0.067 & 0.133 & 0.133 & 0.467 & 0.633 & 0.9 & 0.967 & 1 \\
\hline
\end{tabular}


Table 4 The Mean and Standard Deviation value from Monte Carlo Simulation

\begin{tabular}{|c|c|c|c|c|c|c|c|}
\hline \multirow[t]{2}{*}{ Type of indicators } & \multirow[t]{2}{*}{ Indicators } & \multicolumn{2}{|c|}{$\begin{array}{c}\text { Government } \\
\text { officers }\end{array}$} & \multicolumn{2}{|c|}{ Professionals } & \multicolumn{2}{|c|}{$\begin{array}{c}\text { Business } \\
\text { practitioners }\end{array}$} \\
\hline & & Mean & SD & Mean & $\mathrm{SD}$ & Mean & $\mathrm{SD}$ \\
\hline \multirow[t]{7}{*}{ Economic benefit } & $\mathrm{X}_{11}$ & 5.24 & 1.63 & 5.97 & 1.65 & 6.14 & 1.25 \\
\hline & $\mathrm{X}_{12}$ & 5.17 & 1.42 & 5.89 & 1.72 & 5.77 & 1.35 \\
\hline & $\mathrm{X}_{13}$ & 5.44 & 1.78 & 6.2 & 1.74 & 5.98 & 1.88 \\
\hline & $\mathrm{X}_{14}$ & 4.85 & 1.5 & 5.46 & 1.33 & 6.04 & 1.47 \\
\hline & $\mathrm{X}_{15}$ & 4.29 & 1.67 & 5.12 & 1.62 & 5.29 & 1.53 \\
\hline & $\mathrm{X}_{16}$ & 5.08 & 0.95 & 5.01 & 1.83 & 5.49 & 1.33 \\
\hline & $\mathrm{X}_{17}$ & 5.71 & 1.73 & 5.38 & 1.16 & 5.76 & 1.28 \\
\hline \multirow[t]{8}{*}{ Social benefit } & $\mathrm{X}_{21}$ & 7.17 & 0.99 & 6.59 & 1.33 & 6.31 & 1.34 \\
\hline & $X_{22}$ & 6.19 & 1.65 & 6.1 & 1.63 & 6.78 & 1.49 \\
\hline & $\mathrm{X}_{23}$ & 7.14 & 0.98 & 7.19 & 0.94 & 7.13 & 1.21 \\
\hline & $\mathrm{X}_{24}$ & 6.17 & 1.42 & 5.94 & 1.69 & 6.53 & 1.67 \\
\hline & $\mathrm{X}_{25}$ & 6.56 & 1.58 & 5.87 & 1.39 & 7.18 & 1.55 \\
\hline & $\mathrm{X}_{26}$ & 6.47 & 1.6 & 6.05 & 1.37 & 6.54 & 1.42 \\
\hline & $\mathrm{X}_{27}$ & 5.9 & 1.42 & 5.89 & 1.35 & 5.43 & 1.69 \\
\hline & $\mathrm{X}_{28}$ & 5.54 & 1.56 & 5.88 & 1.47 & 5.61 & 1.95 \\
\hline \multirow{8}{*}{$\begin{array}{l}\text { Environmental } \\
\text { benefit }\end{array}$} & $X_{31}$ & 6.27 & 1.57 & 7.11 & 0.91 & 6.96 & 1.58 \\
\hline & $X_{32}$ & 6.33 & 1.67 & 6.89 & 1.28 & 6.97 & 1.58 \\
\hline & $X_{33}$ & 6.3 & 1.62 & 6.52 & 1.5 & 6.77 & 1.68 \\
\hline & $\mathrm{X}_{34}$ & 6.43 & 1.56 & 6.17 & 1.52 & 6.4 & 1.85 \\
\hline & $X_{35}$ & 6.31 & 1.36 & 6.34 & 1.38 & 6.75 & 1.63 \\
\hline & $\mathrm{X}_{36}$ & 5.32 & 2 & 5.89 & 1.37 & 5.87 & 2.03 \\
\hline & $X_{37}$ & 6.54 & 1.71 & 5.91 & 1.35 & 6.75 & 1.5 \\
\hline & $\mathrm{X}_{38}$ & 6.24 & 1.68 & 6.12 & 1.38 & 5.69 & 2.23 \\
\hline
\end{tabular}


Table 5 The degree of membership of indicators for CAIs

\begin{tabular}{|c|c|c|c|c|}
\hline Indicator & $\begin{array}{c}\text { Government } \\
\text { officers }\end{array}$ & Professionals & $\begin{array}{c}\text { Business } \\
\text { practitioners }\end{array}$ & Integrated \\
\hline & $\mu_{\tilde{A}_{G}}$ & $\mu_{\tilde{A}_{p}}$ & $\mu_{\tilde{A}_{B}}$ & $\mu_{\tilde{A}}$ \\
\hline $\mathrm{X}_{11}$ & 0.569 & 0.656 & 0.805 & 0.805 \\
\hline $\mathrm{X}_{12}$ & 0.448 & 0.681 & 0.673 & 0.698 \\
\hline $\mathrm{X}_{13}$ & 0.619 & 0.722 & 0.656 & 0.726 \\
\hline $\mathrm{X}_{14}$ & 0.414 & 0.521 & 0.718 & 0.718 \\
\hline $\mathrm{X}_{15}$ & 0.379 & 0.426 & 0.574 & 0.574 \\
\hline $\mathrm{X}_{16}$ & 0.372 & 0.434 & 0.622 & 0.622 \\
\hline $\mathrm{X}_{17}$ & 0.578 & 0.464 & 0.703 & 0.704 \\
\hline $\mathrm{X}_{21}$ & 1.000 & 0.817 & 0.745 & $1.000^{*}$ \\
\hline $\mathrm{X}_{22}$ & 0.717 & 0.688 & 0.858 & $0.859^{*}$ \\
\hline $\mathrm{X}_{23}$ & 1.000 & 1.000 & 0.979 & $1.000^{*}$ \\
\hline $\mathrm{X}_{24}$ & 0.777 & 0.644 & 0.817 & 0.827 \\
\hline $\mathrm{X}_{25}$ & 0.809 & 0.613 & 0.855 & $0.864^{*}$ \\
\hline $\mathrm{X}_{26}$ & 0.781 & 0.676 & 0.835 & 0.842 \\
\hline $\mathrm{X}_{27}$ & 0.729 & 0.660 & 0.571 & 0.732 \\
\hline $\mathrm{X}_{28}$ & 0.441 & 0.626 & 0.573 & 0.629 \\
\hline $\mathrm{X}_{31}$ & 0.722 & 1.000 & 0.871 & $1.000^{*}$ \\
\hline $\mathrm{X}_{32}$ & 0.753 & 0.910 & 0.873 & $0.923^{*}$ \\
\hline $\mathrm{X}_{33}$ & 0.777 & 0.818 & 0.833 & $0.856^{*}$ \\
\hline $\mathrm{X}_{34}$ & 0.714 & 0.650 & 0.755 & 0.764 \\
\hline $\mathrm{X}_{35}$ & 0.852 & 0.815 & 0.851 & $0.884 *$ \\
\hline $\mathrm{X}_{36}$ & 0.534 & 0.639 & 0.709 & 0.712 \\
\hline $\mathrm{X}_{37}$ & 0.692 & 0.658 & 0.844 & 0.845 \\
\hline $\mathrm{X}_{38}$ & 0.652 & 0.690 & 0.714 & 0.728 \\
\hline
\end{tabular}

Note: *indicates that the degree of membership is equal or greater than 0.85 . 


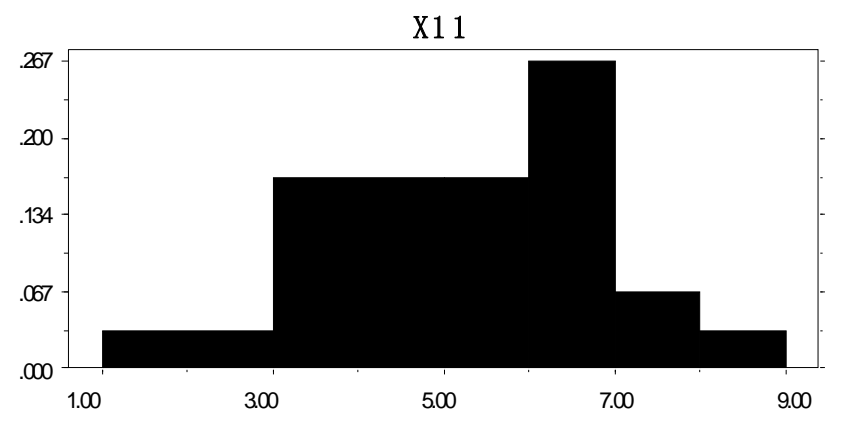

Figure 1 The probability distribution of $X_{11}$ in government officers group 


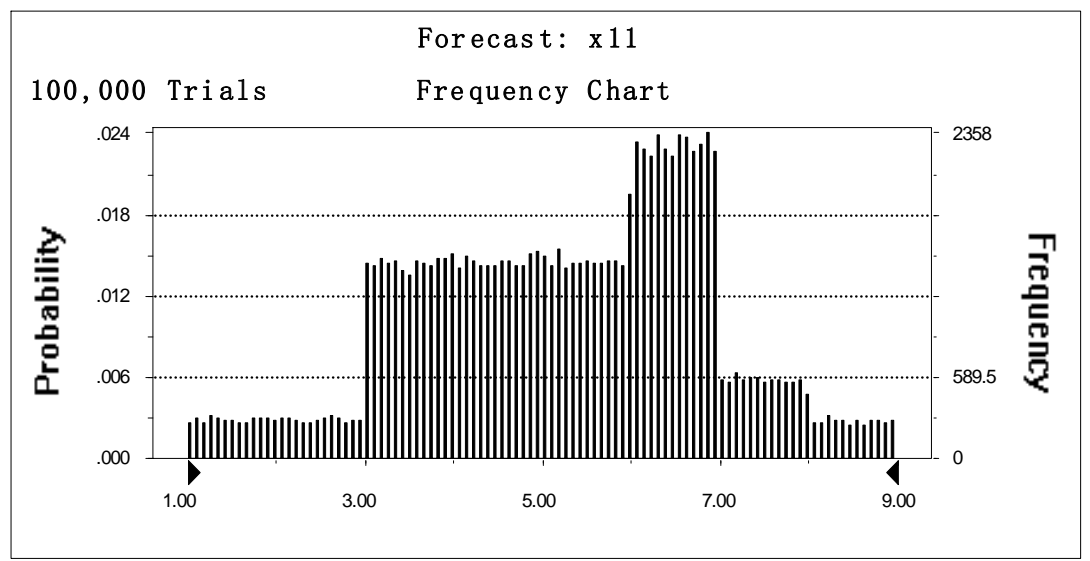

Figure 2 The probability distribution of $\mathrm{X}_{11}$ from government officers group by simulating 


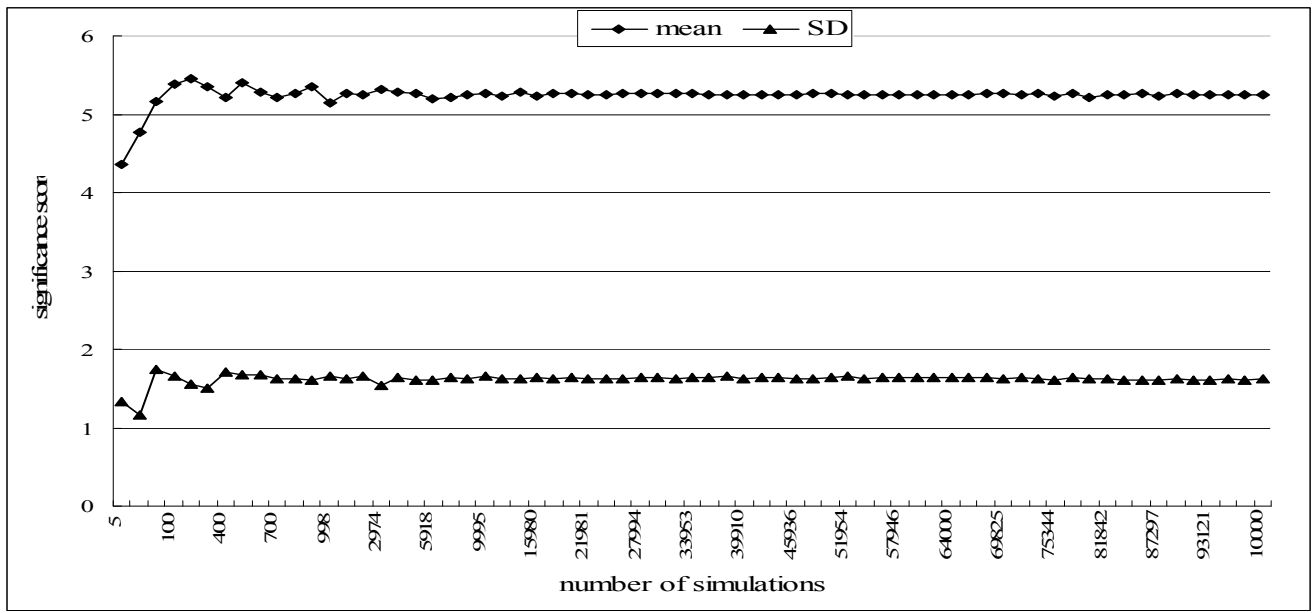

Figure 3 The convergence of mean and SD value for $\mathrm{X}_{11}$ from government officers group by simulating 


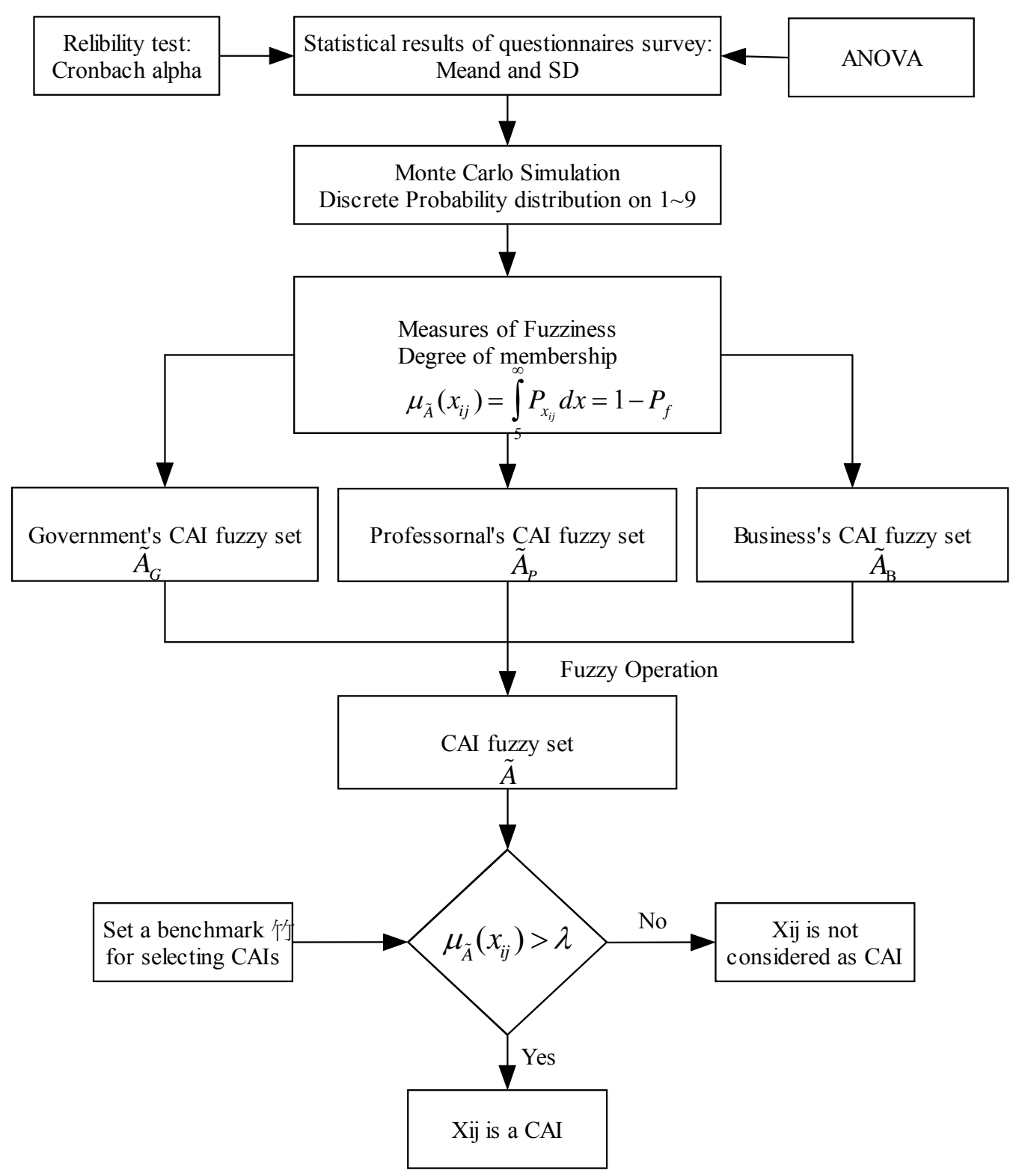

Figure 4 The procedure of selecting CAI based on Monte Carlo Simulation and Fuzzy Set Theory 